\title{
ABC for people with HIV: responses to sexual behaviour recommendations among people receiving antiretroviral therapy in Jinja, Uganda
}

\author{
Caroline Allen $^{\mathrm{a}}$, Martin Mbonye ${ }^{\mathrm{b}}$, Janet Seeley $^{\mathrm{b}, \mathrm{c}, \mathrm{f} *}{ }$ Josephine Birungi $^{\mathrm{d}}$, Brent Wolff ${ }^{\mathrm{b}}$, \\ Alex Coutinho ${ }^{\mathrm{e}}$ and Shabbar Jaffar ${ }^{\mathrm{f}}$ \\ ${ }^{a}$ Caribbean HIV\&AIDS Alliance, Woodbrook, Trinidad and Tobago; ${ }^{b}$ MRC/UVRI Uganda Research \\ Unit on AIDS, Entebbe, Uganda; ${ }^{c}$ School of International Development, University of East Anglia, \\ Norwich, UK; ${ }^{d}$ The AIDS Support Organisation, Kampala, Uganda; ${ }^{e}$ Infectious Diseases Institute, \\ Kampala, Uganda; ${ }^{f}$ London School of Hygiene and Tropical Medicine, London, UK
}

(Received 7 October 2010; final version received 25 January 2011)

\begin{abstract}
People living with HIV who are taking antiretroviral therapy (ART) are increasingly involved in 'positive prevention' initiatives. These are generally oriented to promoting abstinence, 'being faithful' (partner reduction) and condom use (ABC). We conducted a longitudinal qualitative study with people living with HIV using ART, who were provided with adherence education and counselling support by a Ugandan nongovernmental organisation, The AIDS Support Organisation (TASO). Forty people were selected sequentially as they started ART, stratified by sex, ART delivery mode (clinic- or home-based) and HIV progression stage (early or advanced) and interviewed at enrolment and at 3, 6, 18 and 30 months. At initiation of ART, participants agreed to follow TASO's positive-living recommendations. Initially poor health prevented sexual activity. As health improved, participants prioritised resuming economic production and support for their children. With further improvements, sexual desire resurfaced and people in relationships cemented these via sex. The findings highlight the limitations of HIV prevention based on medical care/personal counselling. As ART leads to health improvements, social norms, economic needs and sexual desires increasingly influence sexual behaviour. Positive prevention interventions need to seek to modify normative and economic influences on sexual behaviour, as well as to provide alternatives to condoms.
\end{abstract}

Keywords: HIV/AIDS; anti-retroviral therapy; sexual behaviour; Uganda

\section{Introduction}

The promotion of adherence to antiretroviral therapy (ART) among people living with HIV may be seen as aiming to fulfil a number of public health objectives. These include reduction of illness and death and prevention of further HIV transmission. As well as encouragement to take all prescribed drugs on time, it may involve recommendations such as eating before taking the medication, having a balanced diet, stopping cigarette smoking and avoiding alcohol. With regard to HIV prevention, a central domain for intervention is sexual behaviour. With expanded access to ART, the growing number of people living longer with HIV forms a potential source of infection and may facilitate the spread of drug resistance. Unless people living with HIV consistently practice safer behaviours, they can

\footnotetext{
*Corresponding author. Email: j.seeley@uea.ac.uk
} 
place themselves at risk of sexually transmitted infections, including other strains of HIV, and place others at risk for HIV infection (Auerbach 2004; Crepaz et al. 2006). Thus there is interest in so-called 'Positive prevention' strategies with people living with HIV (Kalichman 2005).

Researchers and organisations advocating on behalf of people living with HIV have noted that positive prevention interventions have tended to focus on individuals, with little inclusion of broader contextual or societal factors favouring infections (Beloqui 2004; Gordon, Stall and Cheever 2004). Recently, The Global Network of People Living with HIV/AIDS and UNAIDS (2009) collaborated to develop the concept of 'Positive health, dignity and prevention', situating responsibilities for prevention within a framework of human rights. Despite increasing acknowledgement of the need to attend to health and dignity as prerequisites and outcomes of effective prevention, reviews of prevention interventions with people living with HIV in developed and developing countries have shown continued concentration on narrow behavioural outcomes (most often condom use) and the predominance of individual or couple-focused education and counselling interventions (Crepaz et al. 2006; Kennedy et al. 2010).

People receiving ART are adjusting their relationships and sexual behaviour to their evolving life prospects, including increasing health and longevity (Russell and Seeley 2010). It is important, therefore, to examine the risks of HIV infection in the context of access to ART and how these change over time (Seeley et al. 2009). Anitretroviral therapy provision may be accompanied by education and counselling that incorporates recommendations on sexual behaviour alongside tips on how to adhere to the medication. HIV prevention recommendations for the general population, revolving around the themes of abstinence, being faithful (reduction in number of partners) and condom use - often known as the ABC approach - may be adapted for people living with HIV.

In this paper we report on a longitudinal study of responses to sexual behaviour recommendations of healthcare providers by people treated with ART in Jinja, Uganda. The study was conducted under near normal health service conditions, meaning that standards of care obtained by participants in the study were similar to those available to other people living with HIV in Jinja.

\section{Methods}

The qualitative study complemented a cluster-randomised equivalence trial of care strategies with 1453 participants (Jaffar et al. 2009) who were recruited when they started ART. The trial rationale was to evaluate home-based care employing lay workers as a care alternative, given barriers to coverage in resource-constrained settings, i.e. difficulty in accessing clinics because of high costs and poor availability of transport and low cash incomes (Hardon et al. 2007) and shortage of clinically qualified staff (Weidle et al. 2006). Healthcare was provided by a large non-governmental organisation, The AIDS Support Organisation (TASO), from a centre in Jinja, one of its 11 centres in Uganda. Care was delivered by TASO according to national guidelines. No financial incentives were given to participants or healthcare workers to participate in the study (Jaffar et al. 2008).

\section{The qualitative study}

The qualitative study was nested inside the main trial. It was designed to chronicle life changes and evolving challenges of adherence among a subsample of 40 trial participants. 
In this paper we focus on the data enabling an understanding of sexual behaviour and prevention among people living with HIV.

Semi-structured interviews using open-ended questions were scheduled at the final enrolment visit before clients had started medication and at 3, 6, 18 and 30 months after enrolment. Home observation visits were conducted on the occasion of all interviews from 3 months onwards, to deepen understanding of environmental and social influences.

The qualitative study sample was stratified to ensure equal numbers of participants by sex, trial arm and clinical/immunological stage, contrasting early and advanced categories (CD4 counts above $150 \times 10^{6} / 1$ or stage I- and II-defining conditions, versus CD4 counts below $100 \times 10^{6} / 1$ or stage III- and IV-defining conditions). A total of 40 participants were recruited in order of appearance between October 2005 and April 2006 until sample quotas for all categories were reached. One male participant died before the end of the enrolment period and was replaced, bringing the sample size to 41 .

To protect confidentiality, a coding system was devised to refer to each participant, with the first letter referring to sex ( $\mathrm{M}$ for male and $\mathrm{F}$ for female), the second to drug delivery mode ( $\mathrm{H}$ for home and $\mathrm{F}$ for facility) and the third to early or advanced HIV stage at enrolment ( $\mathrm{H}$ for high CD4 count or early HIV progression or stage and L for low CD4 count or advanced HIV progression). The clients were also numbered from 1 to 5 within each stratum (or 6 for the stratum including the participant who died). Thus FHL4 is female, home-based, with advanced HIV progression. This coding system has been used when referring to clients in this paper, in addition to pseudonyms.

Semi-structured interview guides were developed based on focus group discussions with TASO providers and ART clients. Guides were administered by social science interviewers (two female and one male), who were separate from the team conducting the trial. Each interviewer enrolled several clients and, to enhance rapport, carried out all interviews and home visits with these participants. All interviews except at enrolment took place at the client's home or, if this was not possible, at the social science office. Sequential recruitment did not allow for matching interviewers and respondents by gender. Interviews were tape-recorded and generally conducted in Luganda and occasionally Lusoga or English depending on interviewee preference. Luganda and Lusoga transcripts were translated into English then checked for accuracy by the interviewer. Interviews lasted about an hour, except the 30-month interviews that lasted about an hour and a half. Home observations were guided by a checklist and interviewees wrote up their observations in English.

In addition to the research with clients, in this paper we draw on documentary sources and discussions with TASO professional staff to describe how risk reduction messages were conveyed from the service provider perspective. Sources include publications about TASO, their website and internal documents. At the end of the trial, two focus group discussions were conducted, one with counsellors based at the TASO facility and one with field officers providing home-based care. Discussion objectives were to get provider perspectives on the role they perceived themselves as playing in the ART delivery programme. Convenience sampling was used based on availability of staff to attend discussions on the scheduled days, given the wish to minimise disruption to care. Of the 15 counsellors, 11 attended the counsellor group and 13 of 14 field officers attended their group. Both discussions were in English.

Analysis looked, on the one hand, at sexual behaviour recommendations as presented in TASO documents, by TASO providers and by the clients. On the other hand, it examined the sexual relationships and practices of clients, how they explained and interpreted them and how they related to social contextual influences. Thematic coding 
was managed using NVIVO 7 software. The initial coding frame was developed following reading of eight transcripts, one from each stratum. Attention was paid to themes of abstinence, 'being faithful' and using condoms, with subsidiary codes examining influences on these. Discussions of abstinence concerned reasons to have or not to have sex at all, while the 'being faithful' category concerned the number of sexual partners. While being open to the full range of explanations put forward by clients and apparent from examination of their circumstances, codes were also informed by prior research on sexual behaviour among people living with HIV, notably Ugandan studies showing the influence of evolving social and economic roles as people attempt to 'normalise' their lives following HIV diagnosis and illness. For example, economically productive and gender roles were examined (Seeley et al. 2009; Russell and Seeley 2010). The initial coding frame was supplemented and modified iteratively as analysis proceeded. Transcripts for each participant were read and analysed consecutively from enrolment to 30 months and for each person an additional document was prepared summarising their 'story' over the study period.

Information sheets and protocols for the trial and qualitative sub-study were approved by the Ugandan National Council of Science and Technology and the Institutional Review Boards of the Uganda Virus Research Institute, the US Centers for Disease Control and Prevention and the London School of Hygiene and Tropical Medicine. Written informed consent was obtained from all clients participating in the qualitative study prior to the enrolment interviews.

\section{Results}

\section{Communication of HIV risk reduction messages by healthcare providers}

The AIDS Support Organisation was founded by volunteers in 1987 and was the first organized community response to the AIDS epidemic in Uganda. It provides medical, counselling, nursing care and (when donations allow) food aid. AIDS advocacy and community outreach are conducted using media including radio and popular theatre.

Counselling is a cornerstone of the TASO approach and has been defined by staff and $\mathrm{HIV}$-infected clients as a dialogue between a counsellor and a client during which issues are discussed, options examined and possible plans for coping made. Coping has been defined as an acceptance of being HIV-infected and having a positive attitude to making the most of each day (Kaleeba et al. 1997).

The AIDS Support Organisation has developed a positive living approach, incorporating sexual behaviour recommendations within a framework that aims to develop emotional and physical resilience, optimism, self-respect, acceptance and openness with others about HIV status, especially within the household (Hampton 1990; Ssebbanja 2007). Since the advent of ART, specific counselling methods have been developed, involving the agreement of the counsellor and client on a 'personal plan' for ART adherence and prevention of HIV transmission. Regarding prevention, this includes identification of types of relationship where HIV transmission may be likely to occur, strategies to handle barriers to safer sexual practice and sources of professional help (Rose 2010). Clients are asked to come to the clinic any time they feel unwell and are given a telephone number to call for advice (Jaffar et al. 2009; Wolff et al. 2009). Counselling is also available during drug collection at the clinic or drug delivery at home.

In focus group discussions, providers emphasised that the approach to behaviour change counselling is iterative: 
We are supposed to make plans, and then you review the previous plans if there is behaviour change. You know behaviour change is gradual. Someone might come the first day and doesn't use condoms and maybe he is finding problems with the condom, then you discuss the sexual issues, and then you say let us try this. Then in the next plan you look at the previous plans, if they are being implemented, if they are not implemented then what is the problem? (Male counsellor, aged 34)

They noted that their efforts to promote safer sexual practice are part of the positive living approach with the aim of strengthening immunity among people living with HIV:

If you follow the positive way, we would find that the CD4 doesn't drop very fast. (Male counsellor, aged 32)

\section{Characteristics of clients participating in qualitative research}

Of participants, 21 were male and 20 female, 21 had drugs delivered at home and 20 came to the facility. Ages ranged from 20 to 62 years, with a median of 39 . Table 1 provides further characteristics of the participants.

The AIDS Support Organisation Jinja clinic serves a predominantly rural and semiurban population from a radius of about $100 \mathrm{~km}$. Most TASO clients are subsistence farmers and very few have waged work in the formal sector (Jaffar et al. 2009). During interviews, respondents revealed a wide range of mostly informal occupations, often shifting from unemployment to various income-earning activities as the study progressed.

\section{Clients' understanding of risk reduction messages}

During enrolment interviews, clients were asked what the counsellors told them about how to take ART drugs. Clients cited sexual behaviour recommendations among the issues presented by counsellors as important in order to improve health while taking ART. Clients used the terms 'rules', 'instructions' or 'guidelines' to refer to the recommendations. Specific disadvantages and sanctions were presented as penalties for breaking these rules, defined in terms of the participant's health status:

They told us that when you follow the instructions the drug will always be effective. So if we don't take what they taught us seriously it means that taking these drugs will be useless. (John, aged 44 [MFL4])

Table 1. Characteristics of study participants $(n=41)$.

\begin{tabular}{lcc}
\hline Characteristic & Number of participants & Percentage of participants \\
\hline Residence & 18 & 44 \\
$\quad$ Rural & 23 & 56 \\
$\quad$ Urban & 17 & 41 \\
Relationship status & 13 & 32 \\
$\quad$ Single/separated & 11 & 27 \\
Married & & 39 \\
$\quad$ Widowed & 16 & 8 \\
Religion & 3 & 41 \\
Catholic & 17 & 12 \\
Pentecostal & 5 & \\
Protestant & & \\
Moslem & &
\end{tabular}




\section{Abstinence}

According to most clients, abstinence was not explicitly recommended by TASO, but certain disadvantages of having sex were highlighted. One was that frequent sex could weaken the person. This point was most often highlighted by men:

Respondent: We are advised to reduce the speed.

Interviewer: What do you mean by speed?

Respondent: I mean having many sexual relationships. Playing sex every day reduces the body's health. (Bosco, aged 39 [MHL4])

Reduction of sexual frequency was integrated among healthy lifestyle recommendations:

She [the counsellor] has been advising me not to smoke again, not to drink alcohol and that I had not to work so hard. I had not to engage myself in sexual issues so much and I had to rest, I

had to eat a balanced diet like meat, milk, green vegetables. (Sam, aged 44 [MFL3])

The issue of weakness through sexual activity was not mentioned by women, who more frequently referred to a general recommendation not to have sex frequently with lots of men or 'Not to involve with men all the time' (Pamela, aged 35 [FFL2]).

Having HIV-infected partners was also discussed, with advice that this brought a risk of re-infection with other HIV strains:

She [your partner] might also be sick and they tell us that ... when you make love with her, the viruses may not be the same and she adds more infections. (Gilbert, aged 32 [MHH4])

In general, clients were encouraged to discuss their desires and sexual relationships with their counsellors so that s/he could help the client to follow their risk reduction plan.

\section{Being faithful}

Messages were more about reducing the numbers of new or casual sex partners than monogamy, or 'sticking to one partner'. This finding may be interpreted in the context of Uganda, where polygamy is common.

The risks of new partnerships were framed in terms of unknown HIV status of partners and possible re-infection and/or transmission, especially if HIV status was not disclosed. Partners, particularly if they were married or long-term, were encouraged to test to find out whether they, too, were HIV-infected. If they were, a programme of counselling for concordant couples was advised. In the case of discordance, messages about the importance of condom use were reinforced and continued counselling encouraged.

Messages about risk reduction within regular partnerships were sometimes seen as stifling sexual expression:

He normally tells me that ... with my wife, we have to use a condom. There is no restriction from having sex with your partner if you feel like, but don't make a mistake and forget a condom just because you are enjoying it. You have to forget about enjoyment. (Geoffrey, aged $62[\mathrm{MHH} 2])$

\section{Condom use}

Counsellors were said to define benefits of condom use in terms of avoiding re-infection with another HIV-strain or sexually transmitted infection or unwanted pregnancy. The dangers of transmission were also highlighted. Counsellors warned against unprotected sex with other people living with HIV, even if they were taking ART: 
They tell us that you may regain strength and wish to have sex with someone who probably is also on ART, that might cause a change in the virus you have, and instead of improving you just become weak again. (Gilbert, aged 32 [MHH4])

Some clients interpreted the counsellors as saying that unprotected sex would strengthen the virus they already had:

Having sex without using a condom you are bringing back the sickness and the virus regains the strength. (Philip, aged 38 [MFH4])

Counsellors emphasised that condoms were freely available from TASO. During field visits, observers noted that a number of clients had condoms from TASO in their homes.

\section{Pregnancy}

The AIDS Support Organisation staff also discussed pregnancy and child-bearing among sexual behaviour recommendations. Risks of pregnancy were said to be weakening of the immune system and the potential for mother-to-child transmission of HIV. Clients were advised that medical assistance and counselling were available in case of pregnancy and that with proper healthcare it was possible to remain healthy and avoid passing on the virus to the baby. If clients wanted to have a baby, they should discuss the options with their counsellor to ensure access to this care:

They said that we don't tell someone not to give birth, but you have to go and tell your counsellor and s/he gives you advice. (Edith, aged 24 [FFH3])

\section{Client responses to sexual risk reduction messages}

\section{To have or not to have sex}

At the time of enrolment interviews, the immediate challenge for clients, especially those with advanced HIV progression, was for their health to recover from a life-threatening state. The response to a question about current sexual activity was usually that the participant was too ill and weak to participate or even think about sexual activity. A few (9, all men) had sex but found it strenuous:

If I slept with a woman for two consecutive days I would feel the heart beating strongly. So, when they told me that you could abstain for two days, I said I could. So, I started reducing. We even stopped having sex and I regained my strength and the heart stopped beating strongly. (Geoffrey, aged 62 [MHH2])

A couple of men shared the view that sex would sap their energy in the same way as would 'holding an axe to split firewood' (Nabaitu, aged 40 [MFL2]) or digging a $10 \times 12$ foot plot of land (Philip, aged 38 [MFH4]). Women believed that sex could damage their health, with Melisa, aged 30 (FHL2), saying that she did not want her partner to 'overwork' her. Participants adopted a cautious and protective approach, being concerned that sex could lead to weight loss (MFL2), re-infection (FHL2), strengthen the virus (FFL2 and FFH2) or fearing that sexual partners would not use a condom (FHH2). Some had developed fear or distaste for sex, based on traumatic circumstances of infection or heartbreak (FFH4, MFL3, MHH4).

The economic status of participants had invariably been severely damaged by prolonged illness. As health improved, they shifted focus from bodily recovery to the achievement of short- and longer-term economic goals. Abstinence was seen by some as a way to focus energy on economic production, with the aim of resuming family responsibilities. A 24-year-old woman had been nursed by her father in extremely poor 
circumstances - they lived in a wattle and mud house where most of the walls had rotted away and the roof was barely balancing on poles. She wanted to prioritise working rather than sex to be in a position to repay the kindness:

If I consider the time ever since I fell sick, a lot of money has been spent on the illness. For you have to eat, you have to drink, passion fruit juice, what not, and when they give you an appointment to come back on such a date you have to go. ... So now, I have to look for work so as to help my father with that money that he has spent while I was sick. So that I also make him happy while he can still see me. (Lillian, aged 24 [FHH3])

Most participants had children and their first economic concern was being able to care for them. A man involved in local beer production said:

Now I do not move around, I do not move in the night, I do not have that time, there is no time I will ever see a girl shaking her bum and I admire her, no ... I only think about my children and what they are going to have for lunch, and thinking about the beer I have to prepare the following day, that will I get money? (Nabaitu, aged 40 [MFL2])

There was a widespread concern that if new partnerships were formed, the new partner would want a child and that this would prevent the respondent from fulfilling his/her responsibilities to existing children, including providing housing (Bosco, aged 39 [MHL4]) or school fees (John, aged 44 [MFL4]). This was regarded as the normal expectation:

If I get a partner she has to deliver more children and it will be a problem again on my side. (Sam, aged 44 [MFL3])

Women were more inclined than men to think that having further children may be seen as inappropriate by those who knew they were HIV-infected, including their own children (FHL2, FFH3, FFL4, FHL2).

Some participants without partners had decided that they would only accept a new partner if s/he was also HIV-infected (FFL2, FFL4, FFL3, FHH2, MHL4). Their concern was to meet people with a common experience of HIV and who would probably be understanding and sympathetic and provide support. The AIDS Support Organisation was seen as a good place to find such partners:

I will go to the office and enquire from my counsellor whether there is a person who is HIVinfected who perhaps shares my opinions. I want to get a person who knows my problem and I will know her problem so that we can remind each other to take the drugs. (Bosco, aged 39 [MHL4])

These participants acknowledged the risk of re-infection with HIV and undertook to use a condom to prevent this.

For those who wanted to abstain, several methods were used to reduce desire or deflect sexual attention. Philip, aged 38 (MFH4) tried not to associate with women, to avoid the temptation to have sex. Peace, aged 48 (FHH4), avoided being in locations where sexual partnerships were formed, rarely leaving her house or going out at night or to bars and adopted a steely countenance:

For someone to propose to you, you may have looked at him in a way that shows interest. Instead, whenever I meet someone I wear a tough face and he fears to say anything. He just passes by. (Peace, aged 48 [FHH4])

At least three women had used disclosure of HIV status as a kind of screening mechanism to include only potential partners who would be supportive (FFH4, FFL3, FFH3).

In the longer term, abstinence became unsustainable or undesirable for most respondents. Reasons for resumption of sexual activity included cementing of existing 
relationships, a felt need for a new relationship and return of sexual desire. Sex with spouses and long-term partners was seen as obligatory once strength had returned. Single, separated and widowed men often obtained a partner for companionship and to carry out household chores.

For men, having a partner was seen as normal once their economic position was secure. For instance, the widower John, aged 44 (MFL4), had resumed working as a fisherman and farming. At 6 months, he indicated he wanted to construct his own house so that he could get a partner (he was living with his brother's family). By 18 months, his fishing boat had been stolen, but he had countered this setback by selling some of his parents' land and using the proceeds to build a house next to the one he shared with his brother's family. John said, 'I am now looking for a partner to get married to because I have a house.' He decided he wanted an HIV-infected partner with whom he could enjoy sex. By 30 months he had met his current partner when they shared transport to collect their drugs at TASO and they lived in the new house.

The satisfaction of economic needs and desires was an important motivation for women to seek or retain a sexual partner (Melisa, aged 30 [FHL2]). In her enrolment interview, FFH1 recounted that she had been abandoned by her husband when she got tuberculosis and became thin. By the 6-month interview, her health had recovered and she had accepted his request to come back to his house and resume the relationship, principally because he controlled a number of resources she needed to improve her economic status and that of her children from a previous relationship. These included banana and maize plantations she had cultivated and some pigs she had reared. She noted that the primary thing she wanted from a relationship was support and that her husband sometimes forced her to have sex. Thus she tolerated sex in an otherwise unsatisfactory relationship because it left her in a stronger economic position:

He has money. And it is mainly what I want from him. He did so many bad things to me but, my friend, you bend for someone because of money. (Melisa, aged 30 [FHL2])

\section{Number of partners}

Nine participants abstained from sex throughout the study, all aged between 30 and 50 years, seven of them were women and two were men. Most sexual relationships were recently formed or a result of separated partners getting back together. Six participants were involved in relationships where they or their partners had other sexual partners.

Marital fidelity was regarded as an important protective strategy for men. Fred, aged 43 (MFH1), thought that his wife was more likely to 'tolerate the condom' than a nonregular partner. Nabaitu, aged 40 (MFL2), thought he had been infected through multiple partnerships and that infection may have been a spiritual sign to remain with his first wife, who had stayed with him while he had 11 children from 4 women: 'If God decided to punish me and he eventually decided to pardon me, let me live like this' (Nabaitu, aged 40 [MFL2]).

Over the 30 months of the study, Dominic, aged 36 (MFH2), married a second wife. He was employed as a peer educator with a non-governmental organisation and met his HIVinfected new wife at TASO through this work. His current wife was also HIV-infected. He believed that having another wife would satisfy his growing sexual desires and prevent him from having 'outside' relationships that might threaten his ART adherence:

It would help me not to go out for more partners because that would cause me problems. This is because if you go out with someone that doesn't know your status or who knows nothing about HIV you will start hiding the tablets from her. (Dominic, aged 36 [MFH2]) 
In rare cases, sexual desire and a need for greater emotional fulfilment led to extra-marital relationships. Fiona, aged 47 (FHH1), had experienced rejection and sexual abuse from her husband. By the 18-month interview she met a new partner while they were both trading in second- hand shoes. She was thrilled with their sexual relationship until he borrowed some money from her and failed to give it back, leading her to sever the relationship. This perhaps illustrates that both desire and male economic support are necessary for relationships to be sustained.

\section{Condom use}

As long as they abstained, the vast majority of respondents supported condom use to prevent HIV transmission and re-infection and vowed to use them if they had sex. Philip, aged 38 (MFH4) and Mercy, aged 22 (FFL4) were worried about condom efficacy and this was one reason they remained abstinent throughout the study.

In practice, resolutions to use condoms appeared easiest to fulfil among married male respondents. These men and their wives knew each others' HIV status and accepted that condom use would protect their health, whether they were HIV-discordant or concordant. Married men generally reported using condoms consistently with their wives. Participant MFH2 noted that he was able to use condoms with both of his wives because 'we have been sensitised together' as they were TASO clients.

Married women generally did not find it as easy to use condoms, though in all cases their husbands knew they were HIV-infected. All reported that condoms were sometimes used. Consistent condom use was reported only by Edith, aged 24 (FHL3), who had sex infrequently as she remained unwell and her husband had two other wives. Condoms were sometimes taken off during sex or refused by husbands. Pamela, aged 35 (FFL2), experienced emotional and physical violence and when she asked her husband to use condoms, his reaction was to attack TASO and her character:

'Condoms!' he replied, and said, 'Woman, is it in the clinic that they tell you those lies! And do you go there to practice prostitution? And you come back here to tell me that we use a condom!'

Nevertheless, she continued to request condom use, in part for contraception as he did not provide sufficiently for their children. He complied occasionally, but refused to have an HIV-test. He died before her 30-month interview.

In enrolment interviews, most respondents resolved that if they were to find a new partner they would both disclose their serostatus and use condoms. However, in practice these two things rarely happened at the same time. In the early days of new relationships, respondents actively sought condom use and were usually successful. However, few disclosed or sought to find out their partner's status at that time. Some thought that using condoms meant that they were preventing transmission and so disclosure was not necessary or could be postponed until the relationship was more stable:

[TASO] always advise us to use condoms and that if we use them we are protecting ourselves and not spreading the virus. So we are using them and there was no use of knowing her health status. (Sam, aged 44 [MFL3])

In a couple of cases, partners found out that the respondent was HIV-infected. The partner of FHL4 had found out from other people but 'did not feel bad about it' as they had been using condoms. The partner of Bosco, aged 39 (MHL4), saw his ART pills and he then disclosed. She disclosed that she was also HIV-infected. They had not yet had sex, but when they did they started using condoms. 
A major difficulty was that, beyond a certain point in most new relationships, condom use could not be sustained. Men found it difficult because it interfered with their pleasure:

It is difficult to stick to condoms after seeing that life has improved. ... Whenever you start engaging yourself in sexual relationships Satan is also near. You can use it for the first time and a time comes when you remember your past times and you remove it. (Bosco, aged 39 [MHL4])

Women's partners often stopped using a condom after they had used it for the initial period of the relationship. The partner of Rashida, aged 30 (FFL3), had used a condom for the first month or so, for their first four sexual encounters, while FHH3's partner used condoms for the first eight months of their relationship. Neither woman had disclosed. When the partners started not to use condoms, each found it impossible to reveal their status. They feared rejection or violence as well as the loss of the plans they had in place as the basis of the relationship. The need to provide for children was a particularly strong motivation for women to avoid disclosure.

\section{Pregnancy and wanting children}

Most respondents already had children and their recovering health led them to prioritise providing for them financially rather than starting new relationships and having more children (see above). There were a few cases (e.g. FFL3, FHL4, FFL2) where unwanted pregnancies arose from male unwillingness to use condoms and female economic dependency on these men. Participants FFL2 and FHL4 assumed their partners wanted a child because they rarely used a condom and had had no children before.

Our study also revealed a few instances where pregnancies were actively sought by participants and/or their partners. Childbearing was widely regarded as a normal, even required, aspect of having a sexual relationship. John, aged 44 (MFL4), had worked hard to build a house and find an HIV-positive partner to live there and at 30 months was delighted to report that his new HIV-positive partner had given birth, especially as he only had one child who did not live with him. Edith, aged 24 (FFH3), had previously been married and her first son had died from measles in early childhood. At her 18-month interview she had a new partner and was pleased that he also wanted children. She had not revealed her serostatus to her partner because she was anxious to see this dream fulfilled.

\section{Discussion}

Our findings highlight the limitations of an HIV prevention model based solely on medical care and personal counselling. As ART improves health, social norms, economic needs and sexual desires play increasingly important roles in influencing sexual behaviour and risk. Other longitudinal research with people living with HIV in Uganda (Seeley et al. 2009; Russell and Seeley 2010) has shown that health improvements resulting from ART enable 'reinstatement into a social world' via endeavours to establish order and control and feel 'normal' again. Thus adherence to ART and sexual behaviour recommendations must be reconciled with social norms about sexual behaviour: married people were expected to have sex with their spouses when they were well enough and childless couples were expected to have a child (Kisakye, Akena, and Kaye 2010). There was also an expectation that, beyond an initial period of courtship, men were not required to use condoms. Other East African studies among both people living with HIV (Undie et al. 2009) and people with unknown or HIV-negative status (Lees et al. 2009) confirm that condom use is difficult to sustain beyond the early days of sexual relationships since ceasing condom use 
symbolises transition from a casual to a regular and committed partnership. Assumed male responsibilities for the economic welfare of their partners in return for sex also played a critical part in influencing sexual behaviour (Desmond et al. 2005). Combined, these norms led to many sex acts being unprotected by condoms and to respondents seeking new or (rarely) additional partners.

Among our findings was that clients were counselled to use condoms consistently with HIV-infected partners to avoid re-infection, with this recommendation apparently given equal weight to other sexual behaviour recommendations. Respondents seemed to understand messages on re-infection but, nevertheless, several of them sought HIV-infected partners ('serosorting'). These findings are interesting in the light of scientific uncertainty about whether re-infection can lead to the development of more virulent or transmissible viruses. There is some evidence that super-infection occurs only rarely in people living with HIV on effective ART (Gonzales et al. 2003; Chakraborty et al. 2004). The search for HIVinfected partners by some clients was motivated by wishes for emotional security, support, sexual fulfilment, avoidance of stigma (Frost, Stirratt, and Ouellette 2008) and, sometimes, parenthood. These aspirations are consistent with broad notions of wellbeing in the emerging Positive Health, Dignity and Prevention discourse (GNP + and UNAIDS 2009). Our findings confirm the view that positive prevention interventions should broaden their focus from narrow behavioural measures such as condom use and incorporate values enabling people living with HIV to lead dignified and emotionally healthy lives.

Most participants in our study were able to resume economic production, but remained in a financially precarious position, barely able to meet basic needs. Women's responsibilities for child welfare, combined with the norm that males provide financially for their partners, led women into relationships in which most of them were unable to secure condom use. A qualitative study among people living with HIV using ART in Kenya likewise found that the need for support for children commonly motivated women to find new partners (Sarna et al. 2009). Along similar lines, a quantitative study of condom use at last sex among people living with HIV in the Caribbean found that economic security of the family positively and independently predicted condom use and that economic security was lower among women than men (Allen et al. 2010). Programmes to improve financial independence among women may reduce intimate partner violence and thus enable women to have more control over sexual behaviour, as has been shown in studies of microfinance initiatives (Kim et al. 2007). In recognition of the challenges posed by economic dependence, especially of women, TASO has been lending some clients small sums to invest and training them in sustainable livelihood projects, though available resources have not been able to reach all clients in need.

Our study shows that, even with access to personalised counselling, approaches that emphasise abstinence, partner reduction and condom use are inadequate in the long term to the task of prevention among people living with HIV. While TASO's messages were quite acceptable to participants, social and economic environmental factors became increasingly important influences as health improved. This implies that a more collective or structural focus of intervention, involving community development and legislative action approaches, should supplement the individualistic personal counselling model (Beattie 1991). It is also clear that condoms, being mostly used inconsistently, are inadequate as a technology to prevent transmission among sexually active people living with HIV. For women it is vital that research continues to develop microbicides and other HIV prevention methods over which they have a greater measure of control than condoms (Heise and Elias 1995). In studies in Africa, male circumcision has been shown to decrease the likelihood of female to male HIV transmission by up to $60 \%$ and may be advocated along with condom use to decrease 
HIV transmission in HIV discordant couples where the female is infected (UNAIDS, WHO and SACEMA 2009). Our findings suggest that Positive Health, Dignity and Prevention require combinations of appropriate biological, behavioural and structural interventions (Padian et al. 2008), tailored to the economic and cultural milieu and informed by an appreciation of the human rights of people living with HIV (GNP + and UNAIDS 2009).

\section{Acknowledgements}

We are grateful to US Centers for Disease Control and Prevention and the UK Medical Research Council for funding this research. We are indebted to Heiner Grosskurth for his support and encouragement throughout the study, to Sarah Nakamanya, Fatuma Ssembajja and Kennedy Bwanika for data collection and to the participants for sharing their time and information so readily and being so supportive of this work. The contents of this paper are solely the responsibility of the authors and do not reflect the official views of the Centers for Disease Control and Prevention or the UK Medical Research Council.

\section{References}

Allen, C., Y. Simon, J. Edwards, and D. Simeon. 2010. Factors associated with condom use: Economic security and positive prevention among people living with HIV/AIDS in the Caribbean. AIDS Care 22, no. 11: 1386-94.

Auerbach, J.D. 2004. Principles of positive prevention. Journal of Acquired Immune Deficiency Syndromes 37, Suppl. 2: S122-25.

Beattie, A. 1991. Knowledge and control in health promotion: A test case for social policy and social theory. In The sociology of the health service, ed. J. Gabe, M. Calnan, and M. Bury, 162-202. London: Routledge.

Beloqui, J.A. 2004. Prevention with people with HIV/AIDS: A perspective from a person living with HIV/AIDS in Latin America. Journal of Acquired Immune Deficiency Syndromes 37, Suppl. 2: S135-7.

Chakraborty, B., L. Valer, C. De Mendoza, V. Soriano, and R. Quinones-Mateu. 2004. Failure to detect human immunodeficiency virus type 1 superinfection in $28 \mathrm{HIV}$-seroconcordant individuals with high risk of re-exposure to the virus. AIDS Research and Human Retroviruses 20, no. 9: 1026-31.

Crepaz, N., C. Lyles, R. Wolitski, W. Passin, S. Rama, J. Herbst, D. Purcell, R. Malow, R. Stall and the HAPRSP Team. 2006. Do prevention interventions reduce HIV risk behaviours among people living with HIV? A meta-analytic review of controlled trials. AIDS 20, no. 2: 143-57.

Desmond, N., C.F. Allen, S. Clift, B. Justine, J. Mzugu, M.L. Plummer, D. Watson-Jones, and D.A. Ross. 2005. A typology of groups at risk of HIV/STI in a gold mining town in north-western Tanzania. Social Science and Medicine 60, no. 8: 1739-49.

Frost, D.M., M.J. Stirratt, and S.C. Ouellette. 2008. Understanding why gay men seek HIVseroconcordant partners: Intimacy and risk reduction motivations. Culture, Health \& Sexuality 10, no. 5: 513-27.

GNP + and UNAIDS. 2009. Positive health, dignity and prevention: Technical consultation report. Amsterdam: The Global Network of People Living with HIV/AIDS.

Gonzales, M., E. Delwart, S. Rhee, R. Tsui, A. Zolopa, J. Taylor, and R. Shafer. 2003. Lack of detectable human immunodeficiency virus type 1 superinfection during 1072 person-years of observation. Journal of Infectious Diseases 188, no. 3: 397-405.

Gordon, C.M., R. Stall, and L.W. Cheever. 2004. Prevention interventions with persons living with HIV/AIDS: Challenges, progress, and research priorities. Journal of Acquired Immune Deficiency Syndromes 37, Suppl. 2: S53-7.

Hampton, J. 1990. Living positively with AIDS: The AIDS Support Organization (TASO), Uganda. London, Nairobi and Colchester, UK: ActionAid/AMREF/World in Need.

Hardon, A.P., D. Akurut, C. Comoro, C. Ekezie, H. Irunde, and T. Gerrits. 2007. Hunger, waiting time and transport costs: Time to confront challenges to ART adherence in Africa. AIDS Care 19, no. 5: 658-65.

Heise, L.L., and C. Elias. 1995. Transforming AIDS prevention to meet women's needs: A focus on developing countries. Social Science and Medicine 40, no. 7: 931-43. 
Jaffar, S., B. Amuron, J. Birungi, G. Namara, C. Nabiryo, A. Coutinho, and H. Grosskurth. 2008. Integrating research into routine service delivery in an antiretroviral treatment programme: Lessons learnt from a cluster randomized trial comparing strategies of HIV care in Jinja, Uganda. Tropical Medicine and International Health 13, no. 6: 1-6.

Jaffar, S., B. Amuron, S. Foster, J. Birungi, J. Levin, G. Namara, C. Nabiryo, et al. 2009. Rates of virological failure in patients treated in a home-based versus a facility-based HIV-care model in Jinja, southeast Uganda: A cluster-randomised equivalence trial. Lancet 374: 2080-9.

Kaleeba, N., S. Kalibala, M. Kaseje, P. Ssebbanja, S. Anderson, E. van Praag, G. Tembo, and E. Katabira. 1997. Participatory evaluation of counselling, medical and social services of The AIDS Support Organization (TASO) in Uganda. AIDS Care 9, no. 1: 13-26.

Kalichman, S.C., ed. 2005. Positive prevention: Reducing HIV transmission among people living with HIV/AIDS. New York: Plenum.

Kennedy, C., A. Medley, M. Sweat, and K. O'Reilly. 2010. Behavioural interventions for HIVpositive prevention in developing countries: A systematic review and meta-analysis. Bulletin of the World Health Organisation 88: 615-23.

Kim, J.C., C.H. Watts, J.R. Hargreaves, L.X. Ndhlovu, G. Phetla, L.A. Morison, J. Busza, J.D.H. Porter, and P. Pronyk. 2007. Understanding the impact of a microfinance-based intervention on women's empowerment and the reduction of intimate partner violence in South Africa. American Journal of Public Health 97, no. 10: 1794-802.

Kisakye, P., W.O. Akena, and D.K. Kaye. 2010. Pregnancy decisions among HIV-positive pregnant women in Mulago Hospital, Uganda. Culture, Health and Sexuality 12, no. 4: 445-54.

Lees, S., N. Desmond, C. Allen, G. Bugeke, A. Vallely, and D. Ross. 2009. Sexual risk behaviour for women working in recreational venues in Mwanza, Tanzania: Considerations for the acceptability and use of vaginal microbicide gels. Culture, Health and Sexuality 11, no. 6: 581-95.

Padian, N., A. Buvé, J. Balkus, D. Serwadda, and W.J. Cates. 2008. Biomedical interventions to prevent HIV infection: Evidence, challenges and way forward. Lancet 372, no. 9638: 585-99.

Rose, N. 2010. TASO ART pathway: Presentation for TASO staff training. Kampala, Uganda: The AIDS Support Organisation.

Russell, S., and J. Seeley. 2010. The transition to living with HIV as a chronic condition in rural Uganda: Working to create order and control when on antiretroviral therapy. Social Science and Medicine 70: 375-82.

Sarna, A., M. Chersich, J. Okal, S.M.F. Luchters, K.N. Mandaliya, N. Rutenberg, and M. Temmerman. 2009. Changes in sexual risk taking with antiretroviral treatment: Influence of context and gender norms in Mombasa, Kenya. Culture, Health and Sexuality 11, no. 8: 783-97.

Seeley, J., S. Russell, K. Khana, E. Ezati, R. King, and R. Bunnell. 2009. Sex after ART: Sexual partnerships established by HIV-infected persons taking anti-retroviral therapy in Eastern Uganda. Culture, Health and Sexuality 11, no. 9: 703-16.

Ssebbanja, P. 2007. United against AIDS: The story of TASO. Oxford and Kampala: Strategies for Hope Trust and The AIDS Support Organisation.

UNAIDS, WHO, and SACEMA. 2009. Male circumcision for HIV prevention in high HIV prevalence settings: What can mathematical modelling contribute to informed decision making? PLoS Medicine 6, no. 9: e1000109.

Undie, C.C., A.K. Ziraba, N. Madise, J. Kebaso, and E. Kimani-Murage. 2009. 'If you start thinking positively, you won't miss sex': Narratives of sexual (in)activity among people living with HIV in Nairobi's informal settlements. Culture, Health and Sexuality 11, no. 8: 767-82.

Weidle, P., P. Wamai, C. Solberg, C. Liechty, S. Sendagala, and W. Were. 2006. Adherence to antiretroviral therapy in a home-based AIDS care programme in rural Uganda. Lancet 368: 1587-94.

Wolff, B., M. Mbonye, A. Coutinho, B. Amuron, R. Nkabala, S. Jaffar, and H. Grosskurth. 2009. High levels of psycho-social readiness for ART in an African population at the outset of treatment. Journal of the Social Aspects of HIV/AIDS 6, no. 3: 105-11.

\section{Résumé}

Les personnes vivant avec le VIH (PVVIH) qui prennent des traitements antirétroviraux s'impliquent de plus en plus dans des interventions en «prévention positive». Celles-ci sont généralement orientées vers une promotion de l'abstinence, de la fidélité (réduction du nombre des partenaires sexuels) et de l'usage du préservatif. Nous avons conduit une étude qualitative 
longitudinale avec des PVVIH sous antirétroviraux, bénéficiant d'une éducation à l'observance et de counselling, offerts par TASO (The AIDS Support Organisation) une organisation non gouvernementale ougandaise. Quarante personnes ont été sélectionnées séquentiellement alors qu'elles débutaient une thérapie antirétrovirale, stratifiées par genre, par mode de délivrance de leur thérapie (centre de soins ou domicile) et par stade de l'infection à VIH (précoce ou avancé); et des entretiens ont eu lieu avec elles au recrutement et à 3, 6, 18 et 30 mois. À l'initiation de leur traitement, les participants ont accepté de suivre les recommandations de TASO sur la «vie positive». Auparavant, leur mauvais état de santé leur empêchait d'avoir une activité sexuelle. Leur santé s'améliorant, les participants ont fait de leur reprise d'activité et du soutien à leurs enfants des priorités. Cette amélioration se confirmant, ils ont retrouvé leur désir sexuel et ceux qui étaient engagés dans des relations les ont renforcées avec des rapports sexuels. Les résultats soulignent les limites de la prévention basée sur les soins médicaux/le counselling personnel. À mesure que la thérapie antirétrovirale améliore l'état de santé, les normes sociales, les besoins économiques et le désir ont un impact croissant sur les comportements sexuels. Les interventions en prévention positive nécessitent une modification des influences normatives et économiques sur les comportements sexuels, ainsi que la mise à disposition d'alternatives aux préservatifs.

\section{Resumen}

Las personas seropositivas que toman antirretrovirales participan cada vez más en las iniciativas para la 'prevención positiva'. En general estas iniciativas están orientadas a fomentar la abstinencia, la fidelidad con la pareja (reducción del número de parejas sexuales) y el uso de los preservativos. Llevamos a cabo un estudio cualitativo y longitudinal con personas seropositivas que toman antirretrovirales a las que una organización no gubernamental de Uganda, la AIDS Support Organisation, ofreció una formación sobre el cumplimiento con la medicación y apoyo psicológico. Se seleccionaron de forma secuencial cuarenta personas que empezaron a tomar antirretrovirales, clasificadas en función del sexo, modo de administrar los antirretrovirales (en una clínica o el hogar), y el estadio de progresión del VIH (temprano o avanzado) y fueron entrevistadas en el momento de inscribirse en el estudio y a los 3, 6, 18 y 30 meses. Al empezar el tratamiento de antirretrovirales, los participantes aceptaron seguir las recomendaciones del programa TASO sobre cómo vivir positivamente. Al principio los participantes evitaban las relaciones sexuales debido a sus problemas de salud. Sin embargo, cuando su salud empezaba a mejorar, los participantes daban prioridad a reanudar la producción económica y apoyar a sus hijos. Con nuevas mejoras, el deseo sexual reapareció y las personas en pareja consolidaron su relación a través de las relaciones sexuales. Estos resultados ponen de relieve las limitaciones en la prevención del VIH basada en la atención médica y el asesoramiento personal. Cuando la salud de las personas va mejorando gracias a los antirretrovirales, las normas sociales, las necesidades económicas y los deseos sexuales influyen cada vez más en la conducta sexual. En las intervenciones para la prevención positiva se debería prestar atención a modificar las influencias normativas y económicas sobre la conducta sexual así como ofrecer alternativas a los preservativos. 